As to diuretics : these medicines are doubtless to be regarded as powerful auxiliaries to other remedial measures; but you will also constantly see that they do not produce the effect anticipated and wished for. This is more especially the case where the disease is of renal origin. The reason of this is obvious, the cause of the disappointment being, that from the morbid condition of the kidneys, those agents which, acting on a healthy organ, would produce the desired effect, have no power over the same when in a state of disease.

In conclusion, I may observe that, to Mr. Huntley, of Howdon, near Newcastle-on-Tyne, I am indebted for the plan of treatment which I now not only advocate, but from which I have obtained such satisfactory results. This acknowledgment I make; not only from a sense of justice, but also as a comparatively small tribute of respect to very considerable practical acumen and experience. If the plan of treatment now recommended be carried out with due care and discrimination, without which any therapeutic agency becomes mere empiricism, you will find that I have not said one word regarding the croton oil treatment of dropsy, which is not more than justified by the facts which I have brought before you.

At a future opportunity, I shall lay before you a tabular statement of the cases treated, with the cause of the disease, the result, and, where fatal, the structural changes.

(To be continued.)

ON THF

\section{INTRODUCTION OF IODOFORM INTO MEDICINAL USE.}

CLAIIY OF M. BOUCHARDAT.

By R. M. GLOVER, M.D., F.R.S.E., \&c.

IN the Bulletin Général de Thêrapeutique for January 15th of the present year, there is a memoir on the therapeutic use of iodoform, with formulas. It is stated very properly, as a reason for employing iodoform, that it contains no less than nine-tenths of its weight of iodine, that very favourable results have been obtained from its use, and, finally, that the "learned Professor has endowed therapentics with a precious agent." It is less with the view of putting in my own claims to the introduction of this interesting remedy than of again calling the attention of the profession to it that I now write. I have submitted more than once in silence, and seer others deck themselves in my plumes, but this is a somewhat special case, and besides, the practice is so common on the other side of the water, that it deserves a rebuke. There is not a single point in which $I$ have not anticipated M. Bouchardat, except in the use of iodoform in cancer, where I firmly believe it will do more harm than good.

The first published notice of the singular physiological properties of iodoform is an account of an experiment on a dog, at which I assisted, published-in Dr. Cogswell's work on Iodine, 1837. In the vear 1842 , in my paper on Bromine and its Compound, published in Craigie's Journal, there will be found a chapter on the Physiological Properties of Chloride and Bromide of Olefiant Gas, Chloroform, Bromoform, and Iodoform, with a note stating that I had used iodoform successfully, both internally and externally, in bronchocele, scrofulous enlargements, and skin diseases; and finally, in the April number of the Edinburgh Monthly Joupnal, 184S, there is a paper by me on the Physiological and Medicinal Properties of Iodoform, where I give a process for the preparation of this substance, the theoretical formula of its preparation, and practical directions for its use, with cases.

The Bulletin de Thérapeutique states that M. Bonchardat gets one-sixteenth of the weight of the iodine he employs in iodoform by bis process. By mine, published in the E'ainbur gh Monthly Journal, I get, I find, one-eighth; and by both processes the excess of iodine of course admits of recovery. I say, "When we consider the' constitution of iodoform, $\mathrm{C}_{3} \mathrm{H}, \mathrm{I}$, so that 13 grains of carbon and hydrogen in this body render about 380 grains of iodine organic-change the iodine from an inorganic to an organic substance, of the same nature as an acid secreted by animals, (the formic, and possessing relations with alcohol and ether, an, assimilable substance;" that, in short, such a body is likely, as well as from its analogy to chloroform, to possess extraordinary properties. The doses in which I recommended it were three grains, in pill, two or three times a day, chiefly in bronchocele and scrofula; externally, half a drachm or a drachm to the ounce of lard in skin diseases and tumours. The doses recommended by M. Bouchardat are nearly the same, except a strong external application to cancer, where I veritably believe it will do harm. In the same article in the Bulletin, it is stated that a $\mathbf{M}$. Rhigini, druggist at Oleggio, had found iodoform to be possessed of anæsthetic properties, but these much feebler than in the case of chloroform. In an article on Anresthesia and Anæsthetic Agents in the British and Foreign Medico-Chirurgical Review, January, 1852, which was written by me, iodoform is classed amongst anæsthetic agents beside chloroform and bromoform; but it is stated " of the bodies analourous to chloroform, bromoform in all probability, and iodoform, certainly, are not sufficiently volatile." I must do THE LANCET the justice to say, that it noticed $m v$ paper on Iodoform, and called the attention of the professinn to it. Now that my results have been confirmed by so listinguished a scientific man as M. Bouchardat, I hope parties may be induced to try the remedy in suitable cases. I may as well say, in case any. one consults my paper, that at p. 579 of the Monthly Journal there is an erratum- $\mathrm{H}_{\mathrm{s}}$ for $\mathrm{H}$

Tavistack-place, February, 1857

ON A CASE OF

\section{CANCER OF THE MAMMA REMOVED BY A PAINLESS METHOD.}

Bx RICHARD BARWELL, EsQ., F.R.C.S., ASSISTANT-SURGBON TO THE CHARING-CBOSS HOSPITAL.

For several years-that is, since 1852- I have been engaged in the study of cancerous diseases, chiefly with a view of finding some constitutional remedy on which reliance could be placed. The question of gradual removal comes naturally into consideration, and I have had such cases where the tumour bore every external character of carcinoma. In the accompanying example, however, all proofs as to the nature of the disease are so clear, so beyond donbt, that I believe the details will be interesting to the readers of THE LANCET.

The treatment adopted requires but few words of explanation. There are, besides the many mineral escharotics, several belonging to the vegetable kingdom, which have the advantage of painlessness; moreover, they hardly act on any but fungoid or lowly organized growths; such are, for instance, oak-bark, the sanguinaria canadiensis, \&c. \&c. In the case below reported, tannic acid was used, because a large surface of diseased growth was open to the action of any application, and because it was deemed advisable to use the least irritating even of vegetable escharotics. I must say that $I$ have failed in finding any especial advantage in removing the tumour en masse, as insisted on by Mr. Haviland in The LANCET of Feb. 14th. Canquoin's pastes, of which he uses the strongest form, are very painful, torturing in only a less degree than arsenical applications. their use has for some years been known and abandoned in all but a very few cases. The mere removal of a carcinomatous growth is very far from being a cure of the disease, and therefore with the local treatment was combined a remedy in which I have learned to place great reliance. I have found that chlorine, given either simply or in combination with soda, acts as a most powerful absorbent and tonic. The weakest and most worn-out system can bear it; it relieves the gastric irritation and rheumatoid pains, so frequently the signs of commencing cancerous cachexia. Even in far advanced cases of uterine disease I have proved the value of this medicine, finding it followed by the above effects, and by a restoration of almost the healthy skin-colour. I hope soon to furnish some examples, wherein the action of this remedy will be fully shown. In the following case it was given in combination with soda (its weakest form), was commenced in a very small dose, increased by tive drops every third clay.

M. H-, aged sixty-two, came to Mr. Canton at the Charing-cross Hospital, with a tumour in the right breast, on the 5th January, 1857. She has borne and suckled seven. children, and suffered eight miscarriages; ceased menstruating at fifty. For some years past has been tronbled with business difficulties; but about Christmas, 1854, more important family troubles deprived her of sleep and appetite; she lost flesh, and has since remained thin In February, 1856 , - that is fourteen 